\title{
REIVINDICAR O DIREITO À CIDADE: COOPERAÇÃO, OCUPAÇÃO, COMUNIDADE
}

\begin{abstract}
Universidade Federal do Espírito Santo
Vitória, Espírito Santo, BR

Resumo

No romance Sunset Park, de Paul Auster, um grupo de jovens fica sem ter onde morar, na esteira da recessão econômica que assolou os Estados Unidos em 2008. Juntos, formam uma comunidade possível numa casa abandonada que invadem e habitam, exercitando formas de cooperação e trabalho em conjunto. O sociólogo Richard Sennett propõe que a cooperação, e a comunidade que nasce da cooperação, podem atuar como saídas para aqueles que se encontram fora da ordem econômica: que os excluídos possam, no exercício da cooperação, voltar o olhar para fora também de suas limitações, ou melhor, das limitações que sempre lhes foram impostas. No romance de Auster, os personagens a todo momento negociam e reconfiguram relações afetivas e econômicas, aprendendo a se abrir para o outro, e colocando-se sempre à margem dos papéis sociais pré-estabelecidos. E esses pequenos deslocamentos, assim como a escrita literária, têm um grande potencial de contaminação, de efetivamente tocar o outro num reconhecimento da potência que nos conforma.
\end{abstract}

Rafaela Scardino

Palavras-chave: Paul Auster; Cooperação; Squatting; Sunser Park

\section{CLAIMING THE RIGHT TO THE CITY: COOPERATION, OCCUPANCY, COMMUNITY}

\begin{abstract}
Paul Auster's Sunset Park tells the story of a group of youngsters that become homeless in the wake of the American economic recession in 2008. Together, they form an alternative society within an abandoned house. By occupying that house, they engage in an everyday practice of cooperation and communal work. Such engagement is analysed through the lenses of sociologist Richard Sennett, who suggests that the cooperation - and the social group that emerges from cooperation - can act as an escape for those who lie outside the economic order. Sennett also proposes that, by cooperating among themselves, those outsiders can look beyond their limitations - or rather the limitations that have always been imposed on them. In Auster's novel, the characters continually negotiate and reconfigure emotional and economic relations, learning to open up to each other, and to put themselves always on the margins of predetermined social roles. And these small displacements, as well as literary writing, have a great potential for contamination, for effectively touching others in a recognition of the power that conforms us.
\end{abstract}

Keywords: Paul Auster; Cooperation; Squatting; Sunser Park 
No romance Sunset Park (2012), de Paul Auster, um grupo de jovens fica sem ter onde morar, na esteira da recessão econômica que assolou os Estados Unidos em 2008. Juntos, formam uma comunidade possível numa casa abandonada que invadem e habitam, exercitando formas de cooperação e trabalho em conjunto. Quando são expulsos da casa que habitavam, não se pode dizer que o romance tenha um "final feliz", mas fica claro o desenvolvimento de habilidades sociais de cooperação e mesmo de criação de vínculos subjetivos pelos protagonistas em sua convivência que, de certa forma, lembra as casas comunitárias descritas por Richard Sennett em seu livro Juntos (2012). Neste livro, o sociólogo volta-se para o estudo da cooperação, enfraquecida, em nossa sociedade, pelas desigualdades e pela homogeneização cultural. No entanto, propõe o estudioso, "voltar o olhar para fora gera um vínculo social melhor do que imaginar que os outros estão refletidos em nós mesmos ou fazer como se a própria sociedade fosse construída como um salão de espelhos" (SENNETT, 2012, p. 333).

As casas comunitárias eram associações de voluntários situadas em comunidades de baixa renda, que ofereciam educação, aconselhamento ou apenas a receptividade de um espaço em que os ocupantes se sentissem acolhidos, e constituíam, conforme definição do autor, "uma experiência de sociabilidade" (SENNETT, 2012, p. 71). Seus ocupantes, assim como os personagens de Auster, eram pessoas paralisadas por suas experiências de perda e exclusão na sociedade capitalista. As casas possuíam, em geral, um organizador comunitário cuja função seria a de estabelecer laços de sociabilidade entre a população da casa, muitas vezes através do incentivo à cooperação: "A questão social nas casas comunitárias tinha, assim, duas frentes: como encorajar a cooperação com outros que diferem e como estimular o puro e simples desejo de associarse" (SENNETT, 2012, p. 69). Os frequentadores dessas casas deveriam, então, exercitar sua capacidade de "olhar para fora" e buscar, no contato com o outro, pontos em comum que possibilitassem a construção de uma melhoria em sua atual situação social, de forma semelhante à estratégia de convivência adotada pelos jovens do romance de Auster.
Em Sunset Park, Miles Heller é um jovem sem fortes vínculos com sua família ou sem maiores perspectivas quanto a seu futuro - traço comum a muitos personagens de Auster - que trabalha "removendo lixo" de casas tomadas pelos bancos aos proprietários que não conseguiram continuar com o pagamento de suas hipotecas. Miles toma para si a tarefa de documentar a desolação que encontra com imagens: tira fotos dos objetos abandonados nas casas cujo lixo, esses mesmos objetos outrora significativos, deve recolher.

Cada casa é uma história de fracasso - de fa-
lência ou de inadimplência, de dívida e de exe-
cução de hipoteca - e ele assumiu a missão
de documentar os últimos vestígios daquelas
vidas desfeitas a fim de provar que as famílias
desaparecidas estiveram ali algum dia, que os
fantasmas de pessoas que ele nunca vai ver e
jamais irá conhecer ainda estão presentes nas
coisas descartadas, dispersas em suas casas
vazias. Miles precisa encontrar os sujeitos que
habitaram aqueles espaços, reconhecer sua pre-
sença para que possa reconhecer algo também
em si. (AUSTER, 2012, p. 07)

Florencia Garramuño analisa a literatura contemporânea a partir de seu trabalho com o que denomina "os restos do real". Tais textos, como a vida mesma, seriam constituídos de "escombros e ruínas que a experiência e os acontecimentos depositam sobre a superfície opaca da existência" (GARRAMUÑO, 2009, p. 96, tradução nossa). A própria experiência aparece como algo incompleto, sempre oblíqua, devendo ser buscada lá onde parece não estar. Uma experiência que não atende ao desejo de saber, à vontade de certeza de uma concepção positiva de sujeitos e identidades. Essa literatura, segundo a autora, busca narrar o inarrável através da proliferação, e responder "ao suposto esgotamento da ficção com a irradiação de novas formas de narrar" (GARRAMUÑO, 2009, p. 20, tradução nossa).

Em Sunset Park, a ânsia de Miles por fotografar tudo o que vê parece relacionar-se a esse movimento da literatura contemporânea descrito por Garramuño. Os objetos fotografados por Miles são descritos como "coisas abandonadas", suas fotografias chegam aos milhares e o que fotografa é, de modo geral, aquilo que 
seria facilmente descartado: meias, bonecas, panelas... Restos da presença de pessoas que foram obrigadas a abandonar suas casas às pressas.

Ainda no contexto do trabalho com a proliferação de restos e da luta pela constituição da experiência, é possível estabelecer linhas de continuidade entre Sunset Park e No país das últimas coisas (AUSTER, s/d), do mesmo autor. Neste último romance, Anna Blume escreve para registrar a destruição da cidade ao seu redor, e também encontra sua subsistência na recolha de destroços, restos de vidas desconhecidas que ficaram para trás. Mas, assim como Miles, acaba por constituir comunidade, e laços afetivos, com outros tão desamparados quanto ela. O início dos dois romances, e as atividades em que se engajam os dois protagonistas "Num mundo que desmorona, num mundo de ruína econômica e de agruras implacáveis e cada vez maiores, remover o lixo é um dos poucos negócios prósperos no setor" (AUSTER, 2012, p. 08), diz o narrador de Sunset Park - deixam clara a continuidade: Miles também habita um mundo de destruição (ainda que agora possamos nomeá-lo, ao contrário da cidade nunca nomeada habitada por Anna), e também ele buscará na constituição de afetos uma possibilidade de resistência.

"Essas são as últimas coisas", são as palavras iniciais de No país das últimas coisas. "Uma a uma, vão desaparecendo para nunca mais voltar. Podia lhe falar das que vi, das que já não existem, mas duvido que haja tempo. Tudo vem acontecendo muito depressa, já não consigo reter os fatos" (AUSTER, s/d, p. 09). O romance de 1987 foi muitas vezes descrito como distópico ou mesmo apocalíptico pela crítica, mas a tentativa de Anna Blume de narrar, ou pelo menos enumerar, as coisas - num sentido amplo, que abrange mais que apenas objetos, mas também pessoas, laços afetivos, subjetividades e a própria cidade - que estavam desaparecendo antes que ela pudesse registrar sua precária existência, estabelece diálogo profundo com as fotografias de Miles, personagem de um romance com fortes referências ao presente de cidades norte-americanas, inclusive no título.

Ele não tem a menor ideia do motivo por que se sente compelido a tirar essas fotos. Compreende que é uma busca vã, sem nenhum pos- sível benefício para ninguém, e mesmo assim toda vez que ele entra numa casa sente que as coisas chamam por ele, falam com ele nas vozes das pessoas que não estão mais ali, pedem a ele para serem olhadas pela última vez, antes de serem descartadas (AUSTER, 2012, p. 09).

Miles fotografa, assim como Anna escreve, para resistir. A proliferação destes "restos do real" nos textos é uma forma de fissurar a separação discursiva que impede o deslocamento e a contaminação entre literatura, vida e política. A memória aparece aqui como exercício colaborativo e ético de impedir o total apagamento do outro, sejam os desabrigados à beira da inanição na cidade sem nome de No país das últimas coisas, sejam as pessoas desalojadas em Sunset Park. O real ultrapassa qualquer possibilidade de explicação ${ }^{1}$ e irrompe no texto através da proliferação de escombros de vidas cujas possibilidades de constituição de experiência se pretende aniquilar. Os objetos fotografados - assim como os objetos reparados do Hospital de Coisas Quebradas de Bing Nathan, futuro companheiro de moradia de Miles Heller - estabelecem uma relação com os que os possuíram, com suas histórias, experiências e afetos, de forma a possibilitar o germe de um desejo de comunidade, como veremos adiante.

Como dito anteriormente, o romance dialoga com a crise econômica de 2008, cuja origem nos Estados Unidos (a mais facilmente identificável, pelo menos) é o setor imobiliário. Sobre tal crise, David Harvey propõe que surge de uma das contradições inerentes ao capitalismo, a contradição existente entre o valor de uso e valor de troca. Acerca de tal fenômeno, o geógrafo escreve que o foco no valor de troca de algo tão fundamental como o direito à habitação gerou um descompasso econômico que submeteu aos influxos do mercado financeiro aqueles que buscavam adquirir uma residência, sem qualquer forma de preparo ou proteção:

Na recente crise do mercado imobiliário nos Estados Unidos, cerca de 4 milhões de pessoas perderam suas casas por execução de hipoteca. Para elas, a busca pelo valor de troca destruiu o acesso ao valor de uso da habitação. Muitas pessoas ainda estão "submersas" em seus financiamentos. [...] A busca irresponsável pelo 
valor de troca destruiu, por fim, a capacidade de muitos de adquirir e, consequentemente, manter seu acesso ao valor de uso da habitação. (HARVEY, 2014, p. 21-22, tradução nossa)

Em Sunset Park, encontramos descrições das reações dos desabrigados inscritas, como rastros, nas casas abandonadas visitadas por Miles. A frustração daqueles que não compreendem, ou melhor, compreendem apenas instintivamente o sistema que lhes custou o direito à moradia, fica registrada nas ações de destruição da propriedade que lhes foi tomada pelo banco, legítimo dono do imóvel frente à inadimplência daqueles que deixaram de pagar a hipoteca, conforme o discurso da ordem. "Rara é a casa que tenha sido deixada em sua condição original por seus antigos donos", escreve o narrador. "Na maioria das vezes, houve uma erupção de raiva e violência, um furor de despedida, um surto de vandalismo arbitrário [...]" (AUSTER, 2012, p. 08). Essas reações viscerais encontrarão certas respostas, certas possibilidades de respostas, nas ações de Miles e seus amigos, quando estes tentarem a instauração de formas de resistência ocupando uma casa vazia à espera de alguma mudança na especulação imobiliária de Sunset Park, bairro pobre e de imigrantes do Brooklyn.

No romance, Sunset Park é descrito como um

território situado entre as ruas 15 e 65 , na zona oeste do Brooklyn, uma vasta babilônia que começa na Upper New York Bay e acaba na Nona Avenida, onde residem mais de cem mil pessoas, entre as quais mexicanos, dominicanos, poloneses, chineses, jordanianos, vietnamitas, brancos americanos, negros americanos e uma colônia de cristãos de Gujarat, na Índia. Armazéns, fábricas, construções à beira do rio, uma vista para a Estátua da Liberdade, o Terminal de embarque do Exército, fechado, [...], uma basílica [...], bares frequentados por bandos de motoqueiros, escritórios que compram cheques, restaurantes hispânicos, o terceiro maior bairro chinês de Nova York, além dos quatrocentos e setenta e oito acres do Cemitério Green-Wood [...]. (AUSTER, 2012, p. 75)

O sociólogo Mark Treskon (2010), no entanto, destaca que o bairro tem chamado cada vez mais a atenção de especuladores e da própria administração munici- pal como uma área com potencial de investimento em construção de edifícios habitacionais. O bairro, tradicionalmente ocupado por populações de imigrantes de baixa renda, vem recebendo ondas de novos moradores com renda mais alta. Os planos de rezoneamento do bairro - algo como os Planos Diretores Urbanos (PDU's) das cidades brasileiras - acabam, de acordo com os moradores, por incentivar a especulação imobiliária e a gentrificação, como ilustrado por um estudo de 2009 da New York University citado por Treskon. Segundo este estudo, entre 2002 e 2009 a administração municipal financiou a construção de 72.000 unidades residenciais destinadas a cidadãos com baixa renda. No mesmo período, entretanto, 200.000 unidades de valor considerado acessível foram perdidas para a especulação. Outro dado relevante é o fato de que o valor determinado pela administração municipal como "baixa renda" - e utilizado, portanto, como índice na criação e preservação de imóveis para essa parcela da população - costuma ser maior do que os valores reais das rendas de moradores de bairros como Sunset Park. Segundo Treskon, "residentes descrevem o processo [de rezoneamento] da cidade como desenhado explicitamente para excluir as existentes populações de baixa renda, minorias e imigrantes e substituí-las por novos residentes mais ricos - e mais brancos" (TRESKON, 2010, p. 290, tradução nossa).

Não apenas Sunset Park é descrito como um lugar morto, de "fúnebre pobreza", mas todo o país aparece, no romance, como uma terra desolada, obcecada com a ideia de progresso a qualquer custo, sem que se possa identificar o que significa tal progresso. A falência do modelo econômico é evidenciada não apenas pela descrição das inúmeras perdas econômicas (ainda que se destaquem os ganhos dos bancos), mas também pelas escolhas dos personagens principais, que decidem, em sua tentativa de resistência comunitária, estabelecer relações que passem ao largo dos intercâmbios monetários.

O “organizador" da casa em Sunset Park é Bing Nathan, percussionista num sexteto de jazz e proprietário do Hospital de Coisas Quebradas, pequena oficina dedicada ao conserto de objetos que não são mais fabricados. Bing é descrito como um homem descontente com o mundo em que vive, e cuja atuação política se encon- 
tra nos pequenos gestos cotidianos, pois já não acredita em mudanças advindas da política partidária. Uma de suas grandes oposições ao chamado American way of life é justamente a obsessão com o progresso. Para Bing,

o conceito conhecido por América está esgotado, [...] o país não é mais uma proposta viável, mas se alguma coisa continua a unir as massas fraturadas dessa nação defunta, se a opinião americana é ainda unânime a respeito de alguma ideia, trata-se da crença na noção de progresso. Ele sustenta que estão errados, que o desenvolvimento tecnológico das últimas décadas só serviu para reduzir as possibilidades da vida. Numa cultura perdulária gerada pela ganância de empresas guiadas pelo lucro, a paisagem se tornou cada vez mais degradada, cada vez mais alienante, cada vez mais vazia de significado e de um propósito sólido. (AUSTER, 2012, p. 68)

A recusa de Bing pelo progresso acaba por ser também, em certa medida, uma recusa por certa concepção futuro, uma descrença em possibilidades de mudança macroestrutural que, no entanto, não lhe impede de ações que abrem fissuras no tecido da ordem, não apenas econômica. Bing, escreve o narrador, "se concentra no local, no particular, nos detalhes quase invisíveis das questões cotidianas" (AUSTER, 2012, p. 67) para "fazer oposição a tudo-isso-que-está-aí, resistir ao status quo em todas as frentes" (AUSTER, 2012, p. 68). Como os organizadores das casas comunitárias descritas por Sennett, concentra-se em experiências por vezes imediatas, mas com potencial de reprodução e ampliação, que podem criar laços de colaboração que acabem por se transformar em produção subjetiva.

Tais posições parecem ecoar aquelas propostas por John Holloway em Fissurar o capitalismo (2013). Neste livro, Holloway propõe uma negação inicial ao modus vivendi capitalista, uma negação da qual surgirão pequenas ações que, criando fissuras na superfície da organização econômico-social dada, acabará por esgarçar o tecido que a constitui. As fissuras nascem de uma atividade de ruptura que é, antes de qualquer outra coisa, produção subjetiva, individual e coletivamente. Fissuras que se opõem a organizações totalitárias, adversas às diferenças. Buscando um discurso que vá de encon- tro às delimitações partidárias, ou ao jargão acadêmico por vezes inacessível aos não-iniciados, Holloway propõe traçar linhas de continuidade entre as muitas lutas e as muitas pequenas ações cotidianas que contribuem para espaços de fuga dentro do capitalismo. "Ao invés de criar divisões bem definidas (entre o líder da guerrilha e a dona de casa [...])", escreve o cientista político,

\begin{abstract}
precisamos achar formas de tornar visíveis e fortalecer estas linhas de continuidade que estão com tanta frequência muito submersas. É por isso que falamos em fissuras: para entender a conexão das nossas múltiplas rebeldias e criações alternativas por meio das linhas de falha invisíveis ou quase invisíveis (e rapidamente cambiantes) na sociedade (HOLLOWAY, 2013, p. 37).
\end{abstract}

Dentre as muitas e diversas formas de fissura descritas por Holloway encontram-se os movimentos autonomistas como o EZLN, a criação de laços comunitários que não estejam guiados por interesses econômicos (ele cita a criação de grupos musicais guiados pelo prazer de produzir música), a instalação de cozinhas populares, a atuação de pessoas que distribuem gratuitamente na internet versões hackeadas de programas de grandes empresas da área de informática e o squat, nome dado à prática de ocupação de edifícios abandonados para sua utilização como residências ou centros comunitários.

Os squatters, também chamados de okupas, opõemse à dinâmica da especulação imobiliária que gerencia os usos das cidades. Suas ocupações de espaços ociosos à espera de uma nova bolha imobiliária são na verdade forma de reivindicar o direito à cidade negado àqueles que se situam às margens do sistema financeiro, sem acesso a empréstimos ou cartas de crédito. Impõem uma revisão do próprio conceito de cidade, pois instauram uma negação das relações econômicas, sociais e espaciais pré-determinadas. Constituem comunidades apenas possíveis, praticáveis. Sua organização é a o do improviso, sempre em movimento - "O que importa é o movimento. A possibilidade das fissuras está em seu mover-se" (HOLLOWAY, 2013, p. 73, grifos no original) - , exercitando o deslocamento como uma forma de organizar a vida mesma. 
Sennett aponta que a cooperação, e a comunidade que nasce da cooperação, podem atuar como saídas para aqueles que se encontram fora da ordem econômica: que os excluídos possam, no exercício da cooperação, voltar o olhar para fora também de suas limitações, ou melhor, das limitações que sempre lhes foram impostas. Os moradores da casa de Sunset Park acabam por criar laços comunitários, mas tais laços, num primeiro momento, não parecem demasiado sólidos ou duradouros. Talvez pela própria característica precária do squatting praticado, que se baseia mais na necessidade individual por moradia que num discurso político organizado; talvez pela própria casa, e o sedentarismo da ação; talvez pelas características específicas dessa comunidade que sequer se estabeleceu: uma dificuldade, frequente nos esforços comunitários, de encontrar no outro, tal qual é, algo em comum. Uma comunidade que nasce da necessidade mais que do desejo e dos afetos acaba por esgarçar o tecido que a constitui.

"A dignidade é uma dança acelerada e saltitante", escreve Holloway (2013, p. 72), apontando para a permanência e a concomitante intermitência dos atos de fissura. Assim, a aparente falência da associação comunitária de Sunset Park é apenas uma das possíveis visões das relações e dos afetos criados nessa experiência no limite do viver juntos. "A dignidade é um saltar, um deslizar, um balançar, um dançar, nunca um marchar: e isto, para o capital, é difícil de perseguir e absorver" (HOLLOWAY, 2013, 77). O reconhecer-se no outro é um esforço de encontrar uma dignidade comum. Em Sunset Park os personagens a todo momento devem reconfigurar relações de gênero, afetivas, econômicas, aprendendo a abrir-se para o outro, e colocando-se sempre à margem dos papéis sociais pré-estabelecidos. E esses pequenos deslocamentos têm um grande potencial de contaminação, de efetivamente tocar o outro num reconhecimento não da igualdade, mas da potência. "Isto nos leva a uma política não de falar, mas de ouvir, ou de ouvir-e-falar, uma política de diálogo, e não de monólogo", escreve Holloway (2013, p. 78). E ainda afirma que, na potência de tocar descontentamentos, a arte tem um papel fundamental, central na organização mesma dos movimentos.
Miles, ao fotografar os objetos abandonados nas casas tomadas pelos bancos, buscava reconhecer a presença dos que já não estavam ali, tentando reconhecer algo em si mesmo nesse movimento. Ao findar do romance, quando os ocupantes da casa de Sunset Park são expulsos pela polícia, Miles se reconhece no desamparo frente às organizações estatais, na falta de um lar: "todos eles agora estão desabrigados, [...] Alice e Bing estão desabrigados, ele está desabrigado, as pessoas na Flórida que moravam nas casas que ele esvaziava estão desabrigadas [...]" (AUSTER, 2012, p. 275-276). Na falta, ele pode encontrar comunidade com os fantasmas que o assombravam nas casas vazias da Flórida.

A comunidade não pode ser pensada fora da noção de processo, ou de um proceder. $^{2}$ A ênfase no como é também uma ênfase estética, que não pode excluir as preocupações éticas do fazer artístico. A literatura como política, como forma propositiva de pensar e de estar no mundo, está voltada para as ações cotidianas, talvez insignificantes, em sua potência de resistência e transformação.

Introduzimos a obra de Ricardo Piglia, mais especificamente o romance Respiração artificial, no qual o personagem Tardewski, em conversa com Emilio Renzi, lhe fala de suas dificuldades para sobreviver: "Sem dinheiro, como ia fazer, não para pensar, mas, mais diretamente, para existir? Comecei a pensar nisso, ou seja, comecei a pensar [...] em como fazer para existir" (PIGLIA, 1987, p. 167). A questão do como, do procedimento, é fundamental para aqueles situados na periferia, os deslocados e os exilados. A essas figuras está reservada a preocupação em continuar vivas, quando sua própria presença é indesejada. Assim, a preocupação em como manter-se vivos é a preocupação de construir uma vida ética, que não seja sujeitada àqueles que, do centro, do discurso de manutenção do status quo, querem impedir seu olhar deslocado e múltiplo, que pode efetivamente criar fissuras.

Em seu prefácio a O que resta de Auschwitz, Jeanne Marie Gagnebin escreve que este texto de Agamben esboça

uma definição de outra ética: não mais uma doutrina das normas (cuja grandeza, mesmo 
obsoleta, ambos [Agamben e Levi] reconhecem), mas uma postura firme e ao mesmo tempo hesitante, incerta, um encarregar-se de transmitir algo que pertence ao sofrimento humano, mas cujo nome é desconhecido (GAGNEBIN, 2008, p. 15).

Tal postura nos parece a da literatura contemporânea que, olhando seu tempo a partir de uma posição deslocada, busca dizer de um viver em que os modos de existir não são simples fatos dados, mas colocam questões políticas de responsabilidade - com o próprio sujeito, com o mundo e com o outro - que possibilitam a fala e, também, a comunidade.

\section{Notas}

1. "Só consigo narrar, não posso fingir compreender", escreve Anna Blume (AUSTER, s/d, p. 25).

2. Termo muito utilizado no hip-hop para se referir ao que se poderia aproximar de uma ética do movimento.

\section{Referências}

AGAMBEN, G. "O autor como gesto”. In: Profanações. Trad. Selvino José Assman. São Paulo: Boitempo, 2007, P. 55-64.

AUSTER, PAUL. No país das últimas coisas. Trad. Luiz Araújo. São Paulo: Best Seller, s/d

Sunset Park. Trad. Rubens Figueiredo. São Paulo: Companhia das Letras, 2012

GAGNEBIN, Jeanne Marie. "Apresentação". In: AGAMBEN, Giorgio. O que resta de Auschwitz: o arquivo e a testemunha. Trad. Selvino J. Assmann. São Paulo: Boitempo, 2008, p. 09-17.

GARRAMUÑO, Florencia. La experiencia opaca: literatura y desencanto. Buenos Aires: Fondo de Cultura Económica, 2009.

HARVEY, David. Seventeen contradictions and the end of capitalism. New York: Oxford University Press, 2014.

HOLLOWAY, John. Fissurar o capitalismo. Trad. Daniel Cunha. São Paulo: Publisher Brasil, 2013.

PIGLIA, Ricardo. Respiração artificial. Trad. Heloísa Jahn. São Paulo: Iluminuras, 1987.

"Una propuesta para el nuevo milênio". In: Margens / Márgenes, n. 2, Belo Horizonte, Mar del Plata, Buenos Aires, out. 2001, p. 1-3.
SENNETT, Richard. Juntos: os rituais, os prazeres e a política da cooperação. Trad. Clóvis Marques. Rio de Janeiro: Record, 2012.

TRESKON, Mark. "Constructing an oppositional community: Sunset Park and the politics of organizing across difference”. In: DESENA, Judith; SHORTELL, Timothy (eds). The world in Brooklyn: gentrification, immigration, and ethnic politics in a global city. Lantham: Lexington Books, 2010, p. 289-312.

Recebido em: 15/07/2016 Aceito em: 07/11/2016 